
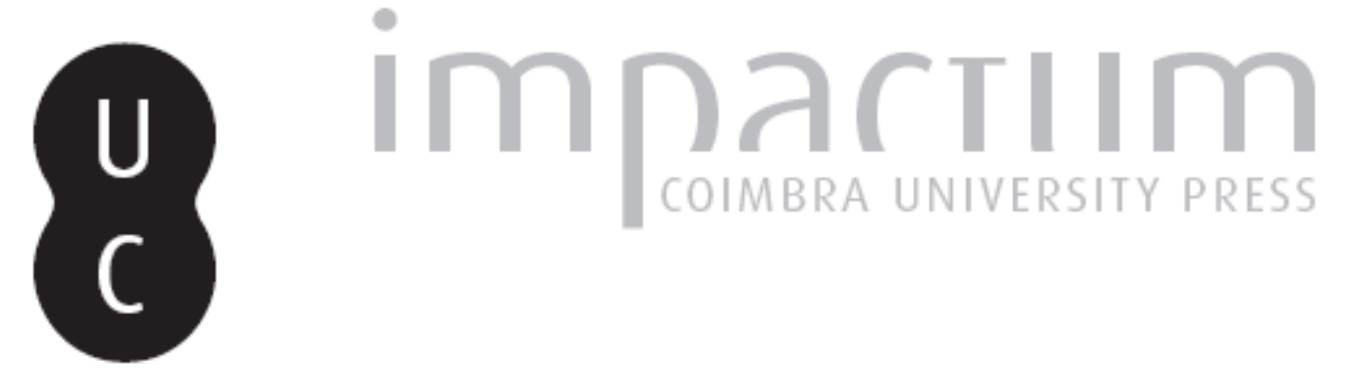

\title{
Processos hidrológicos e hidroquímicos estudados por um geógrafo na sua tese de doutoramento em Ciências Aplicadas ao Ambiente
}

\author{
Autor(es): Rebelo, Fernando \\ Publicado por: Associação Portuguesa de Riscos, Prevenção e Segurança \\ URL \\ persistente: \\ URI:http://hdl.handle.net/10316.2/40165 \\ DOI: \\ DOl:https://doi.org/10.14195/1647-7723_3_6 \\ Accessed : $\quad$ 26-Apr-2023 10:12:35
}

A navegação consulta e descarregamento dos títulos inseridos nas Bibliotecas Digitais UC Digitalis, UC Pombalina e UC Impactum, pressupõem a aceitação plena e sem reservas dos Termos e Condições de Uso destas Bibliotecas Digitais, disponíveis em https://digitalis.uc.pt/pt-pt/termos.

Conforme exposto nos referidos Termos e Condições de Uso, o descarregamento de títulos de acesso restrito requer uma licença válida de autorização devendo o utilizador aceder ao(s) documento(s) a partir de um endereço de IP da instituição detentora da supramencionada licença.

Ao utilizador é apenas permitido o descarregamento para uso pessoal, pelo que o emprego do(s) título(s) descarregado(s) para outro fim, designadamente comercial, carece de autorização do respetivo autor ou editor da obra.

Na medida em que todas as obras da UC Digitalis se encontram protegidas pelo Código do Direito de Autor e Direitos Conexos e demais legislação aplicável, toda a cópia, parcial ou total, deste documento, nos casos em que é legalmente admitida, deverá conter ou fazer-se acompanhar por este aviso.

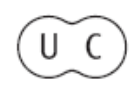




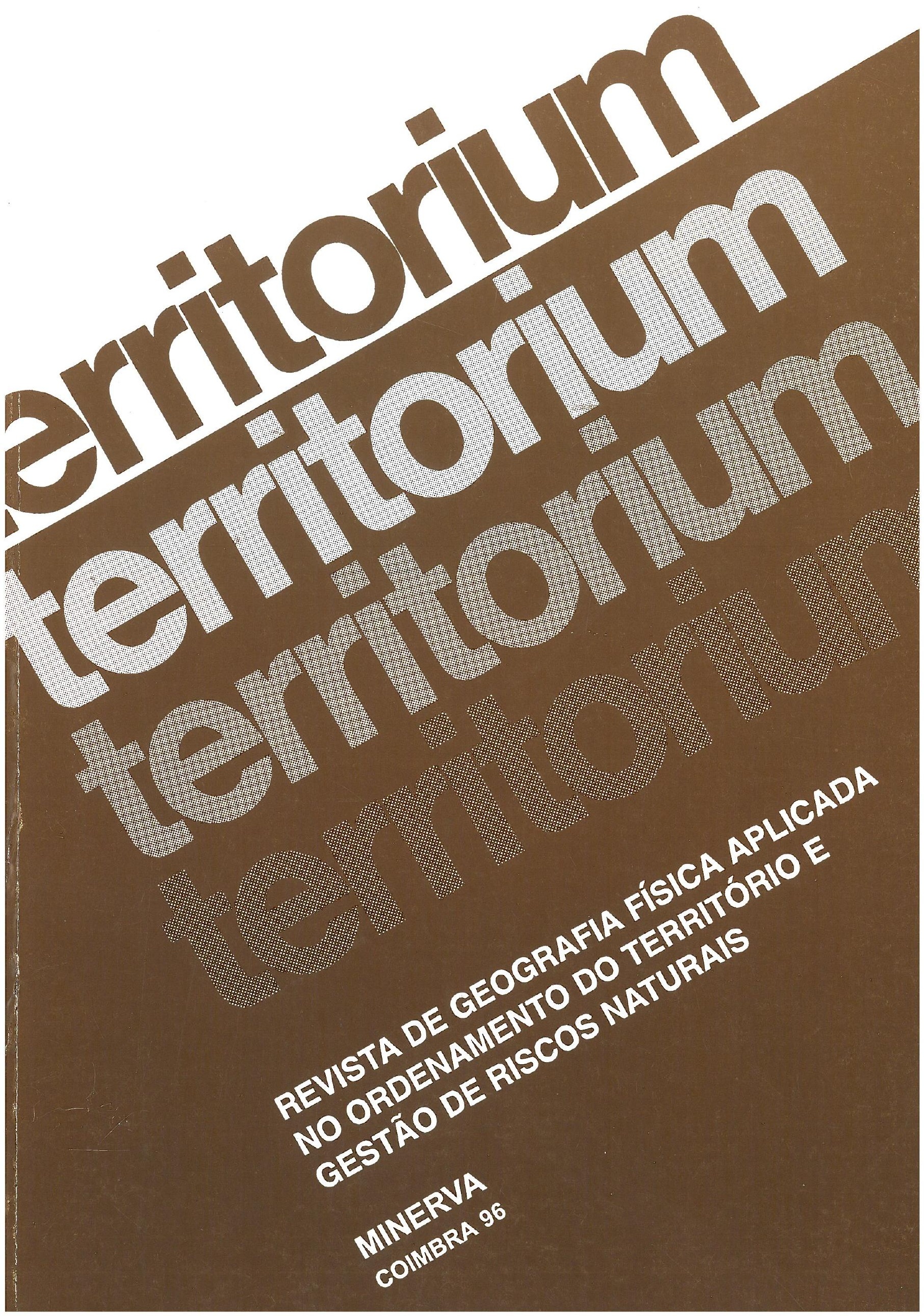




\section{NOTAS, NOTÍCIAS E RECENSÕES}

\section{Processos hidrológicos e hidroquímicos estudados por um geógrafo na sua tese de doutoramento em Ciências Aplicadas ao Ambiente}

\section{Fernando Rebelo}

No passado dia 27 de Junho de 1996, efectuaram-se, em Aveiro, as provas de doutoramento no ramo de Ciências Aplicadas ao Ambiente de ANTÓNIO JOSÉ DINIS FERREIRA. A tese apresentada tem como título Processos hidrológicos e hidroquímicos em povoamentos de Eucalyptus globulus Labill. e Pinus pinaster Aiton. A área escolhida para o estudo situa-se na vertente ocidental da Serra do Caramulo.

Licenciado em Geografia por Coimbra, DINIS FERREIRA dedicou-seà investigação no Departamento de Ambiente e Ordenamento da Universidade de Aveiro tendo elaborado a presente tese sob a supervisão da Professora Doutora Celeste Coelho e a co-orientação do Professor Doutor Rory Walsh, da Universidade de Wales (Swansea), na qualidade de bolseiro do Programa Ciência.

$\mathrm{Na}$ forma policopiada em que se encontra, o trabalho tem um total de 418 páginas, com texto harmoniosamente ilustrado com 7 fotografias de mapas, 84 quadros ("tabelas", como lhes chama o Autor) e 80 figuras; no final, acrescentam-se 31 páginas de "anexos", no caso, mais 32 quadros e 55 figuras. A tese foi estruturada em 9 capítulos sendo que o primeiro é uma rápida "Introdução" (cinco páginas) e o último uma conclusão que tem como título "Conclusões e Síntese" (oito páginas).

Breves apontamentos de carácter geográfico encontram-se no segundo capítulo ("Caracterização da área em estudo") e nos dois seguintes, que já se debruçam sobre as bases de pormenor para o estudo experimental ("Desenho experimental e métodos" e "Caracterização dos solos na área de estudo", respectivamente terceiro e quarto capítulos). Os dois capítulos a seguir correspondem à investigação hidrológica realizada - "Processos hidrológicos na estrutura aérea da vegetação" (quinto) e "Hidrologia de solos" (sexto). Vêm finalmente, e com uma organização sernelhante a estes, os dois capítulos de hidroquímica "Processos hidroquímicos na copa das árvores" (sétimo) e "Hidroquímica dos solos" (oitavo).

Trata-se de um estudo bem estruturado, baseado num bom conhecimento da bibliografia específica sobre processos hidrológicos e hidroquímicos (no total são citadas 462 espécies bibliográficas) e num minucioso trabalho de campo com forte componente experimental. Os dados obtidos foram tratados matematicamente e muitos deles são apresentados sob a forma de gráficos.

A utilidade desta tese para geógrafos, agrónomos e silvicultores parece-nos grande. Aguardamos, portanto, com muito interesse, a sua publicação esperando que nela se venha a salientar, logo no título ou, pelo menos, em subtítulo, a localização da área em estudo, que haja uma melhor ilustração cartográfica e fotográfica dando mais realismo ao texto e mostrando um pouco do que se fez no campo, que se aprofundem as relações do tema com os incêndios florestais, especialmente jogando com o que se sabe sobre o caso concreto do centro de Portugal, e, por fim, que se junte um pequeno glossário com a definição dos termos menos habituais para os leitores portugueses. Será então o momento ideal para fazer uma revisão do texto e para dar mais força às conclusões.

\section{Breve nota sobre o recuo da linha de costa e a intervenção humana a sul da Figueira da Foz}

\section{José Nunes André *}

1. Na generalidade do litoral da Região Centro, tem-se verificado, nas últimas décadas, um défice sedimentar bastante significativo que se traduz num recuo da linha de costa e consequente diminuição

* Mestre em Geografia. Professor na Escola Secundária de Vieira de Leiria. das áreas de praia. Situação idêntica tem-se verificado nas praias portuguesas, com excepção das que, em relação à deriva litoral, se encontram a montante de acidentes naturais, cabos ou promontórios, ou de acidentes artificiais, esporões ou molhes. 